\title{
High repetitive arginine in the anterior of PCV3 capsid protein is a severe obstacle for its expression in E. coli
}

\author{
Bing Yan Liu, Bin Gao, Meng Zhi Liu, Ting Ting Zhang, Bao Shan Liu* and Ze Liang Chen*
}

\begin{abstract}
Porcine circovirus type 3 (PCV3) is a novel circovirus identified in sows with PDNS-like clinical signs and reproductive failure. The capsid protein (CAP) of PCV3 is expected to be an effective vaccine candidate. Here, we expressed the original capsid protein, truncated capsid protein without anterior highly repetitive arginine $(\triangle C A P)$ and their codonoptimized counterparts in E. coli. These results showed that lots of repeated arginine could severely lower the expression of PCV3 capsid protein in E. coli. At the same time, the recombined truncated PCV3 capsid protein forms typic virions. The efficient expression of capsid protein is expected to serve the development of PCV 3 vaccines and other studies of PCV3 capsid protein.
\end{abstract}

Keywords: PCV3, Capsid protein, Expression, High repetitive, Arginine, Obstacle

\section{Key points}

1. High repetitive arginine in the anterior of PCV3 CAP severely hinders its expression in E. coli.

2. The purified recombined $\triangle \mathrm{CAP}$ automatically assemble into typic virions.

3. The efficient expression of CAP serves studies of PCV3.

\section{Introduction}

Circoviruses are a class of the smallest DNA viruses, with a particle size of about $20 \mathrm{~nm}$. Porcine circoviruses include Porcine circovirus 1 (PCV1), PCV2: Porcine circovirus 2 (PCV2), and Porcine circovirus 3 (PCV3). PCV3 is a novel circovirus identified in 2017 in sows with reproductive failure and clinical signs like pig dermatitis and nephrotic syndrome (PDNS) (Palinski et al. 2017).

\footnotetext{
*Correspondence: Ibslgy@syau.edu.cn; zeliangchen@yahoo.com Key Laboratory of Livestock Infectious Diseases in Northeast China, Ministry of Education, College of Animal Science and Veterinary Medicine, Shenyang Agricultural University, No. 120, Dongling Road, Shenyang 110866, Liaoning, People's Republic of China
}

The capsid and replicase proteins of PCV3 are only 37\% and $55 \%$ identical to PCV2 and bat circoviruses, respectively (Palinski et al. 2017). After the first confirmed case in the USA in 2017, PCV3 was subsequently identified in pigs in other countries such as China (Zhai et al. 2017), Italy (Faccini et al. 2017), Poland (Stadejek et al. 2017), Korea (Kwon et al. 2017), Russia (Yuzhakov et al. 2018), Japan (Hayashi et al. 2018), Brazil (Tochetto et al. 2018) Denmark Spain (Franzo et al. 2018) and Sweden (Ye et al. 2018). PCV3 DNA was even detected in the dog (4 of 44 dogs) (Zhang et al. 2018). It is also found that the PCV3 infection increased rapidly from late 2013 to early 2014 (Li et al. 2018). The high occurrence of PCV3 may pose a potential threat to the swine industry worldwide ( $\mathrm{Li}$ et al. 2018). However, the processes resulting in the emergence and spread of PCV3 remain poorly understood (Li et al. 2018). Until today PCV3 has not been successfully cultured in vitro (Deng et al. 2018), which makes it difficult to study its pathogenesis, protein function, and vaccine.

To further study the structure and function of the virus and to develop a vaccine, the viral coat protein needs to be expressed. Prokaryotic expression in E. coli is the most mature and efficient expression method. However, in our previous study, the PCV3 capsid protein was barely 
expressed in E. coli. So to understand the influence factor for the expression of the PCV3 capsid protein, the expression of PCV3 capsid protein in E. coli was tested after codon optimization and truncation.

\section{Methods}

Analysis of the sequence of the capsid protein

For high levels of expression in E. coli, the codon usage of the gene sequence of the capsid protein of PCV3 isolate (MK000387) was analyzed at the online $E$. coli Codon Usage Analysis 2.0 (http://faculty.ucr.edu/ mmaduro/ codonusage/usage.htm.). Then antigenic epitopes of the PCV3 capsid protein (CAP) were analyzed by the online program Bepipred Linear Epitope Prediction 2.0 and ElliPro at the website immune Epitope database and analysis resource (IEDB) (http://www.iedb.org/). Based on the analysis of the sequence, the intact PCV3 CAP and a truncated Capsid protein without anterior 32 amino acids $(\triangle \mathrm{CAP})$ were selected to express. At the same time, both amino acid sequences were codon-optimized for expression in E. coli utilizing the online Reverse Translate program of the Sequence Manipulation Suite (http:// www.bioinformatics.org/sms2).

\section{Construction of expression vector of the capsid protein}

The codon optimization sequences of CAP and $\triangle \mathrm{CAP}$ were synthesized and inserted into $B a m \mathrm{H}$ I and Xho I site of a pET-28a plasmid vector respectively to construct the recombined plasmid $\mathrm{pET}-3 \mathrm{CAP}-\mathrm{O}$ and $\mathrm{pET}-\triangle 3 \mathrm{CAP}-\mathrm{O}$ by Sangon Biotech (Shanghai) Co., Ltd.

Using DNA samples identified as PCV3 positive by PCR (Palinski et al. 2017) as templates, the gene sequences of CAP and $\triangle \mathrm{CAP}$ were amplified by Polymerase chain reaction (PCR) with two pairs of primer (Table 1). After digested by the restriction enzyme $\mathrm{BamH}$ I and Xho I, they were cloned into pET-28a plasmid vector respectively to construct the recombined plasmid pET-3CAP and pET- $\triangle 3 C A P$. The recombinant plasmid was introduced into E. coli BL21 (DE3) cells by transformation using traditional chemical transformation methods.

\section{Table 1 The primers for the sequences of CAP and $\triangle C A P$}

\begin{tabular}{llll}
\hline Probe/primer & The DNA sequence $\left(\mathbf{5}^{\prime} \mathbf{- 3}^{\prime} \mathbf{)}\right.$ & Tm & $\begin{array}{l}\text { Amplicon } \\
\text { size }(\mathbf{b p})\end{array}$ \\
\hline CAPF & ttt ggatcc ATGAGACACAGAGCTATA & 55.40 & 650 \\
& TTCAG & & \\
$\triangle$ CAPF & ttt ggatcc CCCACAGCTGGCACATAC & 58.09 & 554 \\
CAPR & ttt Ctcgag TTCACTTAGAGAACG & 55.31 & \\
& GACTTG & &
\end{tabular}

The lowercase letters are protective bases and restriction sites, respectively
The recombined bacteria with the plasmid $\mathrm{pET}$ 28a, pET-3CAP, pET- $\triangle 3$ CAP, pET-3CAP-O and pET$\triangle 3 \mathrm{CAP}-\mathrm{O}$ were cultured respectively in $5 \mathrm{~mL} \mathrm{ZYP}-5052$ medium in $37{ }^{\circ} \mathrm{C}$ until the $\mathrm{OD}_{600}$ of the cultures reached 0.6 . Then they were transferred to $20^{\circ} \mathrm{C}$ for $12 \mathrm{~h}$ to induce the expression of the recombined protein (Studier 2005).

\section{Expression of the recombined capsid and truncated capsid protein}

The expressed cells were harvested by centrifugation and mixed with sodium dodecyl sulfonate-polyacrylamide gel electrophoresis (SDS-PAGE) loading buffer containing $\beta$-mercaptoethanol for the SDS-PAGE, then loaded on $12 \%$ SDS-PAGE after heating the samples for $10 \mathrm{~min}$ at $100{ }^{\circ} \mathrm{C}$. The polyacrylamide gel was stained using Coomassie Blue for visualizing the protein. The result was taken a photo (Fig. 1a) on a Tanon GIS system (Tanon, China), and protein expression was analyzed quantitatively by the ImageJ software (NIH, USA) basing on the proportion of their grey value in the total grey value.

The recombinant proteins resolved on SDS-PAGE gels were also transferred to the nitrocellulose membrane (Whatman, Germany) using the Mini Trans-Blot Transfer Unit (BIO-RAD, USA) for one hour. The membrane was blocked with $1 \%$ bull serum albumin (BSA) for $1 \mathrm{~h}$ at room temperature and incubated at room temperature for half an hour with anti-his tag monoclonal antibody (Sangon Biotech Co., Ltd., Shanghai, China) (1:5000) in $1 \%$ BSA. After being washed with PBST (50 mM potassium phosphate, $150 \mathrm{mM} \mathrm{NaCl}, 0.05 \%$ Tween $20, \mathrm{pH}$ 7.2) for three times at $5 \mathrm{~min}$ interval, the membrane was incubated with a 1:2000 horseradish peroxidase (HRP)conjugated goat anti-mouse IgG for $0.5 \mathrm{~h}$ at room temperature. After further washing, the signal was detected using the colourimetric substrate $\mathrm{DAB} / \mathrm{H}_{2} \mathrm{O}_{2}$ in the dark place for $15 \mathrm{~min}$.

\section{Purification and identification of the recombinant PCV3 capsid protein}

Wet induced cells of the recombinant $E$. coli expressing $\triangle C A P$ were harvested by centrifugation at $5000 \times g$ for $10 \mathrm{~min}$. The bacterial pellet was washed and resuspended in binding buffer $(20 \mathrm{mM}$ sodium phosphate, $500 \mathrm{mM}$ $\mathrm{NaCl}, 20-40 \mathrm{mM}$ imidazole, $\mathrm{pH}$ 7.4). Cell paste was lysed over 15 passages through the cell disrupter JN-Minipro (JUNENG NANO\&BIO TECH.CO., LTD, Guangzhou, China) at 1000 bar pressure. Cell-lysate was clarified by centrifuging at $12,000 \times g$ for $10 \mathrm{~min}$ to remove the cell debris. Then the supernatant was loaded to a HisTrap FF column (GE, USA), which was connected to an AKTA prime chromatography system (GE Healthcare, Chalfont St. Giles, United Kingdom). After washing with 10 


\begin{tabular}{|c|c|c|c|}
\hline Original gene & 1 & $\triangle \mathrm{TG} A G A C A C A G A G$ & AGA AGA AGA CCC CGC CCA AGG AGA CGA CGA CGC CAC AGA \\
\hline Codon-optimized & 1 & ATG CGC CAT CGC GCG ATT TTT & CGC CGC CGC CCG CGC CCG CGC CGC CGC CGC CGC CAT CGC \\
\hline Amino acid & 1 & 佂T Arg His Arg Ala Ile Phe & 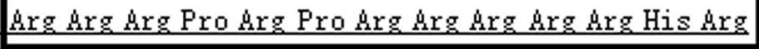 \\
\hline Origi: & 61 & AGG CGC TAT GTC AGA AGA & GC ACA TAC TAC ACA \\
\hline Codon-optimized & 61 & CGC CGC TAT GTG CGC CGC & CTG TTT ATT CGC CGC CCG AC \\
\hline Amino acid & 21 & Arg Arg Trr Val Arg Arg I & Leu Phe Ile Arg Arg Pro Thr AlaGly Thr Tyr Tyr Thr \\
\hline
\end{tabular}

Original gene 121 AMG AMA TAC TCC ACC ATG AAC GTC ATT TCC GTT GGA ACC CCT CAG AMT AMT AMG CCC TGG Codon-optinized 121 AMA ASA TAT AGC ACC ATG AMC GTG ATT AGC GTG GGC ACC CCG CAG AMC AAC AAB CCG TGG Amino acid 41 Lys Lys Tyr Ser Thr MET Asn Val Ile Ser Val Gly Thr Pro Gln Asn Asn Lys Pro Trp

Original gene 181 CAC GCC AAC CAC TTC ATT ACC CGC CTA AMC GAS TGG GAM ACT GCA ATT AGC TTT GAM TAT Codon-optinized 181 CAT GCG AMC CAT TTT ATT ACC CGC CTG AMC GAS TGG GAS ACC GCG ATT AGC TTT GAM TAT Ámino acid 61 His Ala Asn His Phe Ile Thr Arg Leu Asn Glu Trp Glu Thr Ala Ile Ser Phe Glu Tyr

Original gene 241 TAT AMG ATA CTA AMG ATG ASA GTT ACA CTC AGC CCT GTA ATT TCT CCA GCT CAG CAM ACA Codon-optinized 241 TAT ABA ATT CTG AHA ATG AMA GTG ACC CTG AGC CCG GTG ATT AGC CCG GCG CAG CAG ACC Amino acid 81 Tyr Lys Ile Leu Lys MET Lys Val Thr Leu Ser Pro Val Ile Ser Pro Ala Gln Gln Thr

Original gene 301 AAA ACT ATG TTC GGG CAC ACA GCC ATA GAT CTA GAC GGC GCC TGG ACC ACA AAC ACT TGG Codon-optinized 301 AMA ACC ATG TTT GGC CAT ACC GCG ATT GAT CTG GAT GGC GCG TGG ACC ACC AAC ACC TGG Amino acid 101 Lys Thr MET Phe Gly His Thr Ala Ile Asp Leu Asp Gly Ala Trp Thr Thr Asn Thr Trp

Original gene 361 CTC CAM GAC GAC CCT TAT GCG GAA AGT TCC ACT CGT AMA GTT ATG ACT TCT AMA AMA AMA

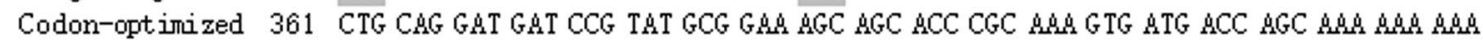
Amino acid 121 Leu Gln Asp Asp Pro Tyr Ala Glu Ser Ser Thr Arg Lys Val liET Thr Ser Lys Lys Lys

Original gene 421 CAC AGC CGT TAC TTC ACC CCC AMA CCA ATT CTG GCG GGA ACT ACC AGC GCT CAC CCA GGA Codon-optimized 421 CAT AGC CGC TAT TTT ACC CCG A A CCG ATT CTG GCG GGC ACC ACC AGC GCG CAT CCG GGC Amino acid 141 His Ser Arg Tyr Phe Thr Pro Lys Pro Ile Leu Ala Gly Thr Thr Ser Ala His Pro Gly

Original gene 481 CAM AGC CTC TTC TTT TTC TCC AGG CCC ACC CCA TGG CTC AMC ACA TAT GAC CCC ACC GTT Codon-optimized 481 CAG AGC CTG TTT TTT TTT AGC CGC CCG ACC CCG TGG CTG AAC ACC TAT GAT CCG ACC GTG Amino acid 161 Gln Ser Leu Phe Phe Phe Ser Arg Pro Thr Pro Trp Leu Asn Thr Tyr Asp Pro Thr Val

Original gene 541 CAM TGG GGA GCA CTG CTT TGG AGC ATT TAT GTC CCG GAM HAS ACT GGA ATG ACA GAC TTC Codon-optimized 541 CAG TGG GGC GCG CTG CTG TGG AGC ATT TAT GTG CCG GAM AMS ACC GGC ATG ACC GAT TTT Amino acid 181 Gln Trp Gly hla Leu Leu Trp Ser Ile Tyr Val Pro Glu Lys Thr Gly MET Thr Asp Phe

Original gene 601 TAC GGC ACC AMA GASGTT TGG ATT CGT TAC AAG TCC GTT CTC TAA Codon-optimized 601 TAT GGC ACC AMA GAM GTG TGG ATT CGC TAT AMA AGC GTG CTG TAM Amino acid 201 Tyr Gly Thr Lys Glu Val Trp Ile Arg Tyr Lys Ser Val Leu ***

Fig. 1 Expression and identification of recombinant PCV3 capsid proteins expressed in E. coli. a The SDS-PAGE analysis of the recombined capsid protein of PCV3. M, protein marker; 1, control bacteria with pET-28a; 2, the bacteria with pET-3CAP; 3 , the bacteria with pET- $\triangle 3$ CAP; 4 , the bacteria with $\mathrm{pET}-3 \mathrm{CAP}-\mathrm{O} ; 5$, the bacteria with $\mathrm{pET}-\triangle 3$ CAP-O. $\mathbf{b}$ Western blots analysis of the expressed recombined proteins using the anti-His antibody. The blot corresponds to lanes 1-5 from (a). The arrows represent the location of the recombined $\triangle \mathrm{CAP}(25 \mathrm{kDa})$, respectively. The expression of the recombined CAP protein did not be detected

column volumes of binding buffer, the $\triangle \mathrm{CAP}$ protein was eluted with the binding buffer containing 50, 100, $300 \mathrm{mM}$ imidazole, $\mathrm{pH}$ 7.2. The collected fractions were identified by SDS-PAGE gels and Western-blot assay with positive serum of PCV3 and HRP-conjugated goat antipig IgG (No.D111051, Sangon Biotech Co., Ltd., Shanghai, China).

\section{Transmission electron microscopy (TEM)}

Two $\mu \mathrm{g}$ of purified $\triangle \mathrm{CAP}$ were adsorbed onto a carboncoated copper grid and incubated for about $1 \mathrm{~min}$. Then, grids were dried using filter paper, negatively stained with $2 \%$ of phosphotungstic acid (PTA) for about $40 \mathrm{~s}$, and viewed using an HT7700 transmission electron microscope (Hitachi, Japan), operating at $120 \mathrm{kV}$. 


\section{Results}

Analysis of the sequence of the capsid protein

The analysis of the codon usage of the sequence of PCV3 capsid protein showed that $23 \%(51 / 214)$ of the PCV3 codons were rare codons for E. coli (Fig. 2). The N-terminal of the capsid protein is especially rich in arginine, where there are 22 arginines among the top 40 amino acids, accounting for $55 \%$.

The results of the antigenic epitopes predicted by the online program Bepipred Linear Epitope Prediction 2.0 and ElliPro found that no linear epitopes or discontinuous B cell epitopes were detected in the first 33 amino acids of the coat protein, which indicates that the $\mathrm{N}$ terminal 33 amino acids can be deleted without affecting antigenicity of the protein (Fig. 3). So, to determine the influence of high repetitive arginine in the expression of the E. coli, the intact PCV3 Cap (CAP) and a truncated Cap without anterior 32 amino acids $(\triangle \mathrm{CAP})$ were selected to express. At the same time, the codonoptimized Cap gene sequence was submitted into the GeneBank as Gene Accession Number MT452640. The codon-optimized $\triangle \mathrm{CAP}$ gene sequence came from the codon-optimized Cap gene. They all were expressed to determine the influence of rare codon and dense arginine by comparison with that of the innate CAP and $\triangle$ CAP gene.

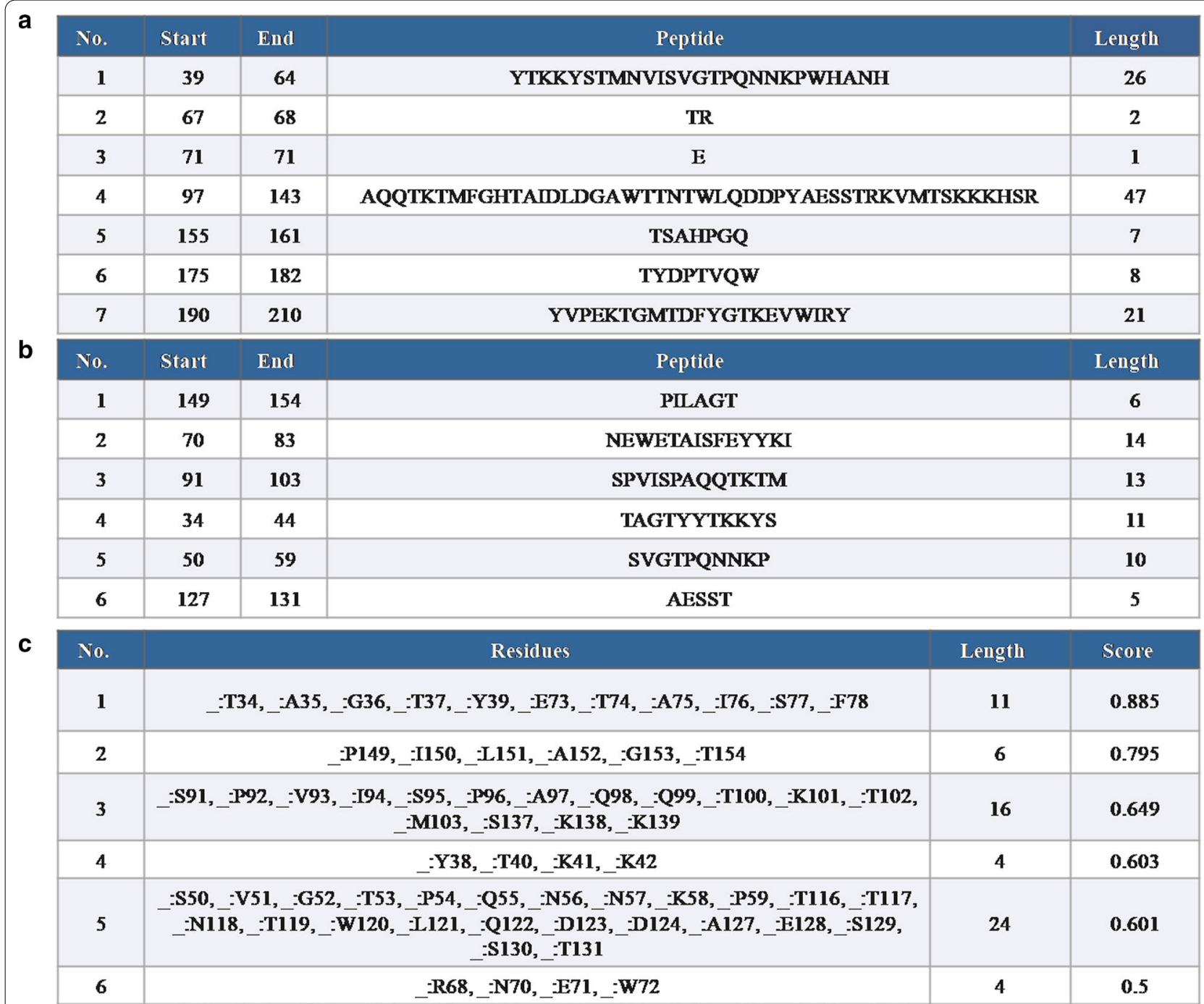

Fig. 2 Codon analysis of PCV3 capsid protein. The original gene of CAP protein has 23\% rare codon (51/214) analyzed by online E. coli Codon Usage Analysis 2.0, which were replaced in the codon-optimized sequence without changing the amino acid sequence. The codon in the shadow represents a rare codon. The underlined sequence was removed in the truncated CAP protein ( $\triangle C A P)$. The concentrated arginines area is in the box 


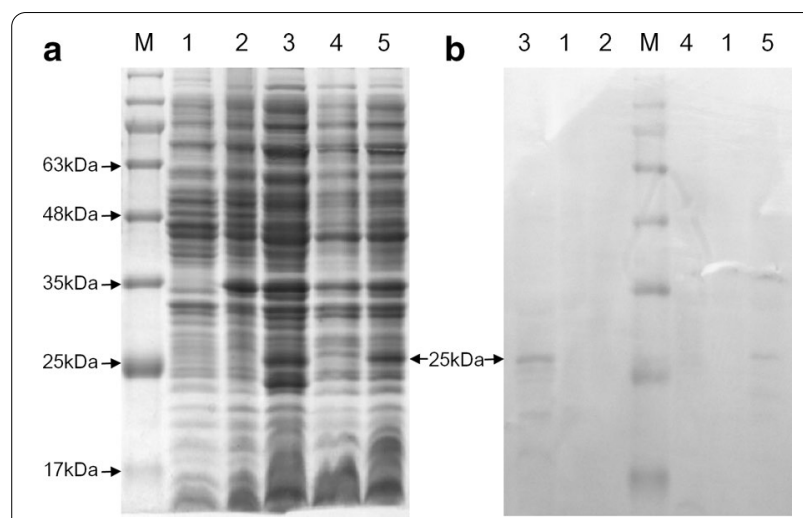

Fig. 3 Antigen Epitope analysis of PCV3 capsid protein at the website immune Epitope database and analysis resource (IEDB). a A list of linear epitopes predicted by Bepipred Linear Epitope Prediction 2.0; $\mathbf{b}$ A list of linear epitopes predicted by ElliPro; $\mathbf{c} A$ list of discontinuous $B$ cell epitopes predicted by ElliPro

\section{Expression of recombining capsid protein}

The construct recombined bacteria containing the pET28a, pET-3CAP-O, pET- $\triangle 3$ CAP-O, pET-3CAP, and pET- $\triangle 3 C A P$ vector were cultured in $5 \mathrm{~mL}$ ZYP-5052 medium for $24 \mathrm{~h}$ for expression of capsid protein. Then $1 \mathrm{~g}$ expressed cells harvested were used for the SDSPAGE. The results showed that two obvious $25 \mathrm{kD}$ protein bands appeared in the lands of recombined bacteria pET- $\triangle 3 C A P-O$ and pET- $\triangle 3 C A P$, respectively, whereas the lands of negative bacteria and recombined bacteria pET-28a, pET-3CAP-O and pET-3CAP had no corresponding bands (Fig. 1a). It indicated that the codon optimation of CAP did not increase its expression in E. coli, but the truncation did. The grey value analysis of bands in the photo of SDS-PAGE showed that the recombinant $\triangle \mathrm{CAP}$ in the bacteria containing $\mathrm{pET}-\triangle 3 \mathrm{CAP}-\mathrm{O}$ and pET- $\triangle 3 C A P$ were constituted $6.2 \%$ and $6.1 \%$ of the total bacteria proteins, respectively (Table 2 ). It showed that the optimization of codon usage increased the expression of capsid protein to a negligible extent. On the other hand, it further reflects the extent to which the truncated processing improves the expression. In the western-blot, the proteins in both bands of $\triangle \mathrm{CAP}$ were recognized by the antibody against 6 His-tag, respectively, but no band

Table 2 The grey value of expressed $\triangle$ CAP band and total bacteria analyzed by the ImageJ software

\begin{tabular}{lcc}
\hline & $\begin{array}{l}\text { Bacteria } \\
\text { with plasmid pET- } \\
\boldsymbol{\Delta 3 C A P}\end{array}$ & $\begin{array}{l}\text { Bacteria } \\
\text { with plasmid pET- } \\
\boldsymbol{\Delta} \text { 3CAP-O }\end{array}$ \\
\hline Expressed $\triangle \mathrm{CAP}$ & 8067.335 & 5409.92 \\
Total & 132229.8 & 87124.77 \\
Percent of expressed $\triangle \mathrm{CAP}$ & $6.1 \%$ & $6.2 \%$ \\
\hline
\end{tabular}

appears in both lanes of recombined CAP (Fig. 1b). It further showed that the optimization of codon did not affect the expression.

\section{Purification of the recombinant $\triangle C A P$ protein}

The recombinant $\triangle \mathrm{CAP}$ from $E$. coli with the pET$\triangle 3 \mathrm{CAP}-\mathrm{O}$ plasmid was purified using Ni-NTA column according to the manufacturer's instruction. SDS-PAGE gels identified three fractions. The $\triangle \mathrm{CAP}$ with a purity of $95 \%$ mainly appeared in the elution with $100 \mathrm{mM}$ imidazole and migrated as one defined band with $26 \mathrm{kDa}$ (Fig. 4a). Western-Blot assay with positive serum of PCV3 and goat anti-pig IgG (Sangon Biotech Co., Ltd., Shanghai, China) showed that the positive serum of pig also recognized the proteins in the bands with PCV3 infection (Fig. 4b). It manifested that the recombine protein is the capsid protein of $\mathrm{PCV} 3$, and it has immunoactivity.

\section{Transmission electron microscopy (TEM)}

The purified $\triangle \mathrm{CAP}$ in the elution with $100 \mathrm{mM}$ imidazole was observed under transmission electron microscopy (TEM). There existed numerous particles with similar morphology of circovirus (Xiao et al. 2018) and the diameter ranging from 15 to $20 \mathrm{~nm}$ (mean $17 \mathrm{~nm}$ ), which were the same homogenous in size and morphology as PCV2 virus particles (Fig. 5). So, the result showed that the $\triangle$ CAP purified from the E. coli cells was assembled into virus-like particles (VLP).

\section{Discussion}

In our present study, we investigated which factor of the rare codon or the dense arginine is a more important obstacle in the expression of PCV3 Cap protein. To

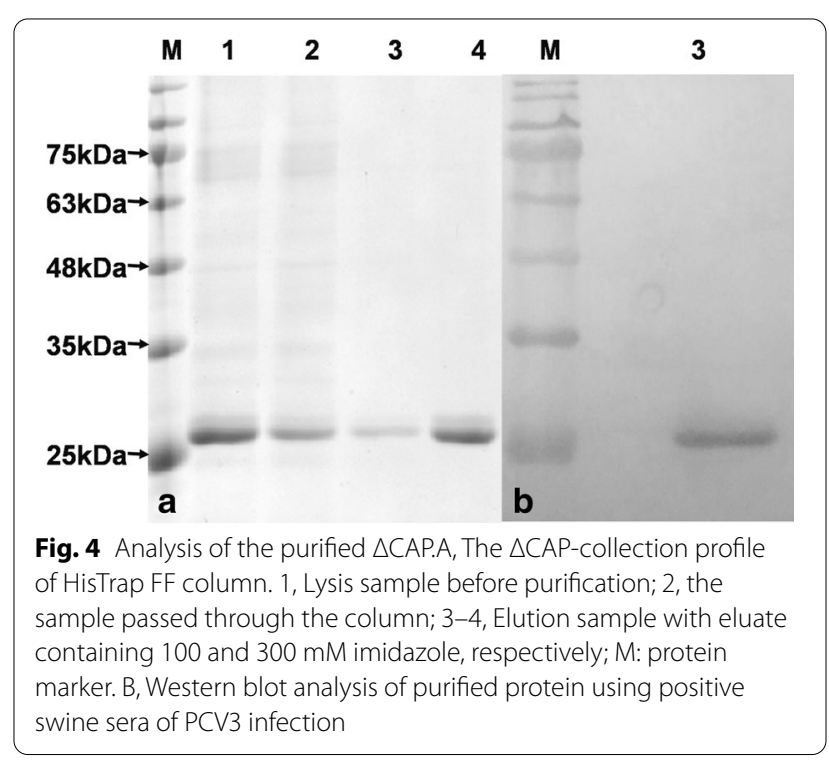




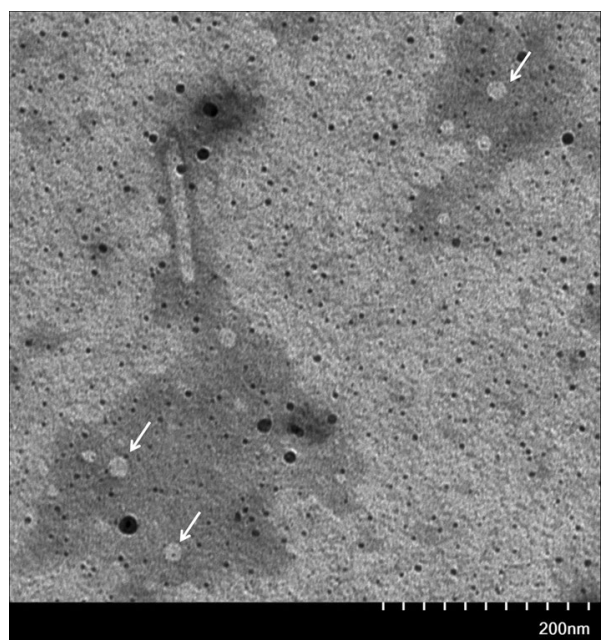

Fig. 5 Transmission electron micrographs of $\triangle C A P$. Virus-like particles (VLPS) formed by purified $\triangle C A P$ proteins expressed in E. coli cells were viewed using an HT7700 operating at $120 \mathrm{kV}$

clarify it, innate, codon-optimized, truncated, truncated and codon-optimized CAP proteins were expressed in E. coli. Our results showed that the deletion of anterior high repetitive arginine could improve the expression of Cap protein in E. coli and didn't influence the formation of virus-like particles.

Rare codon analysis showed that the anterior N-terminal of PCV3 capsid protein contained a large number of rare codons, which were concentrated and repeated (Fig. 2). For the expression of a protein in the pET28a expression vector, the number of rare codons and their concentration degree are the important affecting factors (Karimi et al. 2015; Nouri et al. 2016). So the innate Cap protein almost wasn't expressed in E. coli, while the truncated Cap protein was obviously expressed.

Moreover, after optimizing the rare codon, the expression of the whole and truncated Cap still showed a huge difference. Although the truncated CAP protein still contained a large number of rare codons, its expression was similar to the codon-optimized truncated cap protein. This demonstrated that highly repetitive arginine is a more obvious obstacle in the expression of PCV3 capsid protein in $E$. coli than rare codons. To the best of my knowledge, this is the first report of the effects of repeat codons in the expression of PCV3 Cap protein. Whether this effect also occurs on other amino acids in other proteins requires further study.

It is reported that PCV2 capsid protein without a nuclear localization signal (NLS) still forms virus-like particles (VLP), which were less homogenous in size and morphology than the typic circovirus (Zhou et al. 2005; Xiao et al. 2018). The VLP formation of purified PCV3 $\triangle \mathrm{CAP}$ was also examined in this study. The VLPs of $\triangle C A P$ had typic circovirus morphology and size. The differences of VLP of truncated Cap protein of PCV2 and PCV3 may be due to viral proteins and truncated region.

PCV3 is being a new focus of attention in all pig-producing areas of the world, so developing a vaccine is a need. Because PCV3 has not been successfully cultured so far (Deng et al. 2018), the expression of antigen in vitro becomes the first choice for vaccine preparation. For a vaccine, capsid proteins must be expressed efficiently at low production costs. The prokaryotic expression system is the most appropriate. The results of this study are conducive to the high expression of PCV3 Cap protein for the preparation of subunit vaccines to prevent and control the PCV3 infection.

In conclusion, the study proved that the main obstructive factor of the expression of PCV3 CAP protein in $E$. coli was high repetitive arginines located in its anterior region. Rare codon has few influences on its expression in E. coli. The truncated capsid protein without the anterior concentrated arginines could be assembled into intact viral protein. It provides a preliminary reference for the production of the recombinant $\mathrm{PCV} 3$ capsid protein for the vaccine or other studies.

\section{Acknowledgements}

Not applicable.

\section{Authors' contributions}

LBS designed the study and drafted the manuscript. LBY, GB, LMZ, and ZTT performed experimental work. All authors contributed to the critical review and revision of the manuscript. All authors read and approved the final manuscript.

\section{Funding}

This work was supported by the Education Department of Liaoning Province (LSNFW201710, LSNYB201612) and the National Key Program for Infectious Disease of China (2018ZX10732401-001, 2018ZX10101002-002). They played no role in the design of the study and collection, analysis, and interpretation of data and in writing the manuscript.

\section{Availability of data and materials}

All data generated or analyzed during this study are available from the corresponding author on reasonable request.

Ethics approval and consent to participate Not applicable.

\section{Consent for publication}

Not applicable.

Competing interests

The authors declare that they have no competing interests.

Received: 11 May 2020 Accepted: 8 December 2020

Published online: 11 December 2020

\section{References}

Chae C (2012) Commercial porcine circovirus type 2 vaccines: efficacy and clinical application. Vet J 194:151-157 
Deng J, Li X, Zheng D, Wang Y, Chen L, Song H, Wang T, Huang Y, Pang W, Tian K (2018) Establishment and application of an indirect ELISA for porcine circovirus 3. Arch Virol 163:479-482

Faccini S, Barbieri I, Gilioli A, Sala G, Gibelli LR, Moreno A, Sacchi C, Rosignoli C, Franzini G, Nigrelli A (2017) Detection and genetic characterization of Porcine circovirus type 3 in Italy. Transbound Emerg Dis 64:1661-1664

Franzo G, Legnardi M, Hjulsager CK, Klaumann F, Larsen LE, Segales J, Drigo M (2018) Full-genome sequencing of porcine circovirus 3 field strains from Denmark, Italy and Spain demonstrates a high within-Europe genetic heterogeneity. Transbound Emerg Dis 65:602-606

Hayashi S, Ohshima Y, Furuya Y, Nagao A, Oroku K, Tsutsumi N, Sasakawa C, Sato T (2018) First detection of porcine circovirus type 3 in Japan. J Vet Med Sci 80:1468-1472

Karimi Z, Nezafat N, Negahdaripour M, Berenjian A, Hemmati S, Ghasemi Y (2015) The effect of rare codons following the ATG start codon on expression of human granulocyte-colony stimulating factor in Escherichia coli. Protein Expr Purif 114:108-114

Kwon T, Yoo SJ, Park CK, Lyoo YS (2017) Prevalence of novel porcine circovirus 3 in Korean pig populations. Vet Microbiol 207:178-180

Li G, He W, Zhu H, Bi Y, Wang R, Xing G, Zhang C, Zhou J, Yuen KY, Gao GF, Su S (2018) Origin, genetic diversity, and evolutionary dynamics of novel porcine Circovirus 3. Adv Sci (Weinh) 5:1800275

Nouri HR, Karkhah A, Varasteh A, Sankian M (2016) Expression of a chimeric allergen with high rare codons content in codon bias-adjusted Escherichia coli: Escherichia coli BL21 (DE3)-codon plus RIL as an efficient host. Curr Microbiol 73:91-98

Palinski R, Piñeyro P, Shang P, Yuan F, Guo R, Fang Y, Byers E, Hause BM (2017) A Novel porcine circovirus distantly related to known circoviruses is associated with porcine dermatitis and nephropathy syndrome and reproductive failure. J Virol 91:e01879-e01816

Stadejek T, Woźniak A, Miłek D, Biernacka K (2017) First detection of porcine circovirus type 3 on commercial pig farms in Poland. Transbound Emerg Dis 64:1350-1353

Studier FW (2005) Protein production by auto-induction in high density shaking cultures. Protein Expr Purif 41:207-234
Tochetto C, Lima DA, Loiko APMV, Paim MR, Scheffer WP, Herpich CM, Cerva Jl, Schmitd C, Cibulski C, Santos SP, Mayer AC, Roehe FQ PM (2018) FullGenome Sequence of Porcine Circovirus type 3 recovered from serum of sows with stillbirths in Brazil. Transbound Emerg Dis 65:5-9

Xiao Y, Zhao P, Du J, Li X, Lu W, Hao X, Dong B, Yu Y, Wang L (2018) High-level expression and immunogenicity of porcine circovirus type $2 \mathrm{~b}$ capsid protein without nuclear localization signal expressed in Hansenula polymorpha. Biologicals 51:18-24

Ye X, Berg M, Fossum C, Wallgren P, Blomström AL (2018) Detection and genetic characterization of porcine circovirus 3 from pigs in Sweden. Virus Genes 54:466-469

Yu C, Li X, Liu J, Diao W, Zhang L, Xiao Y, Wei H, Yu Y, Yu Y, Wang L (2016) Replacing the decoy epitope of PCV2b capsid protein with a protective epitope enhances efficacy of PCV2b vaccine. Vaccine 34:6358-6366

Yuzhakov AG, Raev SA, Alekseev KP, Grebennikova TV, Verkhovsky OA, Zaberezhny AD, Aliper TI (2018) First detection and full genome sequence of porcine circovirus type 3 in Russia. Virus Genes 54:608-611

Zhai SL, Zhou X, Zhang H, Hause BM, Lin T, Liu R, Chen QL, Wei WK, Lv DH, Wen $X H$, Li F, Wang D (2017) Comparative epidemiology of porcine circovirus type 3 in pigs with different clinical presentations. Virol J 14:222

Zhang H, Qian P, Peng B, Shi L, Chen H, Li X (2015) A novel subunit vaccine coexpressing GM-CSF and PCV2b Cap protein enhances protective immunity against porcine circovirus type 2 in piglets. Vaccine 33:2449-2456

Zhang J, Liu Z, Zou Y, Zhang N, Wang D, Tu D, Yang L, Deng Z, Yang Y, Jiang P, Wang $N$ (2018) First molecular detection of porcine circovirus type 3 in dogs in China. Virus Genes 54:140-144

Zhou JY, Shang SB, Gong H, Chen QX, Wu JX, Shen HG, Chen TF, Guo JQ (2005) In vitro expression, monoclonal antibody and bioactivity for capsid protein of porcine circovirus type II without nuclear localization signal. J Biotechnol 118:201-211

\section{Publisher's Note}

Springer Nature remains neutral with regard to jurisdictional claims in published maps and institutional affiliations.

\section{Submit your manuscript to a SpringerOpen ${ }^{\circ}$ journal and benefit from:}

- Convenient online submission

- Rigorous peer review

- Open access: articles freely available online

- High visibility within the field

Retaining the copyright to your article

Submit your next manuscript at $\boldsymbol{\nabla}$ springeropen.com 